\title{
THE IMPLEMENTATION OF THE LEADER APPROACH IN SLOVAK REPUBLIC, IDENTIFICATION OF PROBLEMS AND POSSIBLE SOLUTIONS
}

\section{Petra Zaujecová, Pavol Schwarcz}

Slovak University of Agriculture in Nitra, Slovakia

\begin{abstract}
The paper deals with the integrated development in rural areas realized by the LEADER approach. This approach is based on the territorial principle, where the significant role are playing local actors operating in the area, who through their actions influence it's development. The LEADER approach is being implemented through the Axis 4 of the Rural Development Policy. The main objective of the paper is to evaluate the implementation of the LEADER approach in particular Local Action Groups in Slovakia, to identify problems with implementation and to suggest solutions for their elimination. In the paper we evaluate the internal operation of the Local Action Group - the balance of relations between members, defining areas of their mutual cooperation and participation rate in the calls from the perspective of managers of Local Action Groups as well as external relations - relations with Agricultural Paying Agency and ways of influencing the operation of Local Action Groups through legislation. We also focuses on personal views of managers on meeting the needs of the Local Action Group by the projects realized within the Axis 4 LEADER. We also pointed out problems connected with the direction of the Axis 4 in terms of the possibility of funds spending, we defined negative impacts of the legislation as well as particular activities of the Agricultural Paying Agency on Local Action Group's performance.
\end{abstract}

Keywords: Integrated Rural Development, LEADER approach, Local Action Group, rural population

\section{Introduction}

Integrated rural development is an innovative approach of rural development, in which supply of external resources and capital assets is essential and contribute to the formation of partnerships and to the development of the region by involving all stakeholders at this level.

Rural development is enhaced by potential involvement of the village into the microregion - voluntary association of municipalities and cities with the aim to solve common problems of the area, to find opportunities for development and through them to improve the quality of life in rural areas (Ondrejka, 2009).

The only instrument for integrated rural development in EU development policy is LEADER approach.

Niemi and Ahlstedt (2007) consider as the objective of the LEADER approach methodology of the linking and the mobilization of the people and LAG's for cooperation in the rural development area with a focus on communication on development opportunities, development of cooperation between the private and public administration as well as improving of cooperation at all levels.

According to Biderman et al. (2004) is such an association a grouping of individuals and entities that are characterized by the sharing of resources and motivation to achieve a change in the economic, social and environmental conditions based on a collective effort in the defined area and is named „partnership".

The members of the partnership should be those who have something to say to the performance of partnership, representatives of government, local government, business and non-governmental sector should be involved.

Each of the representatives specifically contribute to the partnership. Representatives of government are important because of their knowledge of legislative standards and competences of particular governmental bodies. The disadvantage is the limitation of their budgets and the inability to exceed the competences. Representatives of local governments deal with governance and are executors of the law, they have a budget for realization of competencies at the local level. The disadvantage is the risk of conflict because of their link with political parties, low flexibility and level of innovation. Entrepreneurs represent the driving force of the local economy. They are the source of job opportunities, contribution to the partnership are their field experiences (know-how). The disadvantage is their strong focus on their own activities. The NGO sector can be considered as a bonding element of partnership, mobilising and integrating the community. The disadvantage are low resources and no legal power (Fekete, 2000).

The way to achieve positive change in the partnership in an effective way is to integrate managerial decision, with impact on the legislation or volunteering (Tuba, Szomolaj and Kovacs, 2006).

Important role in partnership plays social capital. Coleman (1990) argues that social capital consists of relationships within groups and between groups, consisting of contacts within and between networks (groups).

By Lin and Erickson (2008) definition of social capital focuses on the „resources enshrined in social relations and social networks." Usually it is seen as a collective good, which is based on a permanent exchange of whether symbolic or material circumstances, creating confidence, solidarity and the cohesion inside of group of individual members of society.

Putnam (2000) by the division of the social capital on the linking and binding refers to the fact that strong social links and reciprocal exchange relations within the community may not only have a positive character. Social networking in a homogeneous social environment, based on close contacts of people forms strong relations, thereby strengthens group identity, creates internal cohesion and solidarity inside the group of people, but may have an exclusionary effect in relation to the rest of the social environment, which might be reflected by the elite social segregation and exclusionary effects. Linking type of social capital is characteristic by the weaker social relations by the intensity, but with a broader scope, with a tendency to cross social boundaries and build bridges between differentiated social groups they reinforce the general social cohesion.

Activation of social capital through public-private partnership, is now visible in many countries and has become an important agenda of EU 
Regional Policy. It represents the significant trend for regional development since it enriches the typically exogenous policy of investment incentives by endogenous access to support and funding of human and social capital (Hudec et al., 2009).

\section{Material and methods}

Within the research, we focus on evaluation of the implementation of the LEADER approach in particular Local Action Group (LAG's). Data were collected through interviews with managers of LAG's in all regions of Slovakia. In total, all 29 LAG's were adressed by questionnaires. The return rate of the questionnaire represented $79 \%$. The questionnaire was compiled to obtain qualitative and quantitative data. It consisted of closed and open questions, decision-making, evaluation and opinion questiones. Closed questions are connected to the selection of several response options of the Likert's word scale with clearly defined differentiation in balance in positive and negative direction along with the ability write own answer.

\section{Results}

For the effective operation of the LEADER approach legislative and institutional correlation is very important, as well as established rapport with local inhabitants.

\section{Internal functioning of the local action group}

Based on the research, most of respondents said that the representatives of local government are the initiators of the forming of the partnership, enterpreneurs initiated the establishment of two partnerships only. Answers of other respondents are shown in Figure 1.

By the analysis of the relationship between LAG members, we found that in the most of LAG's its members cooperate together, and if not, their interest to cooperate is obvious. According to the statements of some managers, there may be found competitiveness among members in some LAG's. Opinions of other respondents are shown in figure 2.

Research indicates that cooperation between LAG members is mostly presented during projects preparation and organization of events. Other areas of cooperation of LAG members are illustrated in Figure 3.

Relations between the private and public sectors can be considered in most LAG's as good, as strained can be considered in one LAG only. The most active sector is the public one (in $74 \%$ of

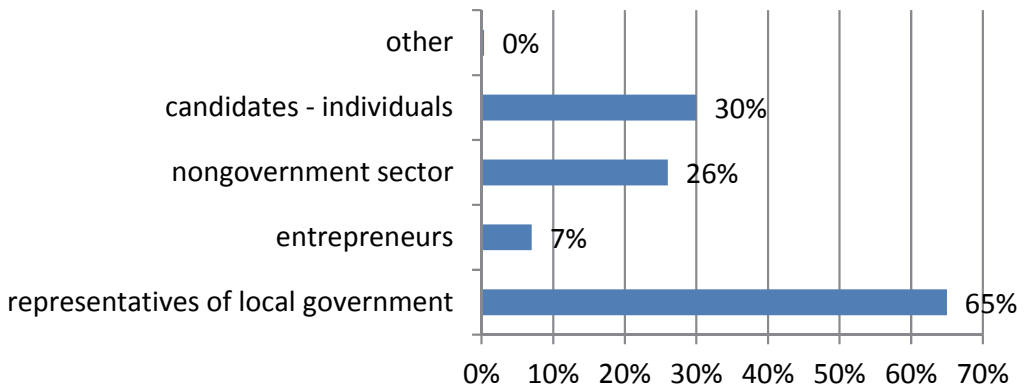

Figure 1 Opinions on initiators of formation of LAG Source: own processing on the basis of questionnaire research, 2014

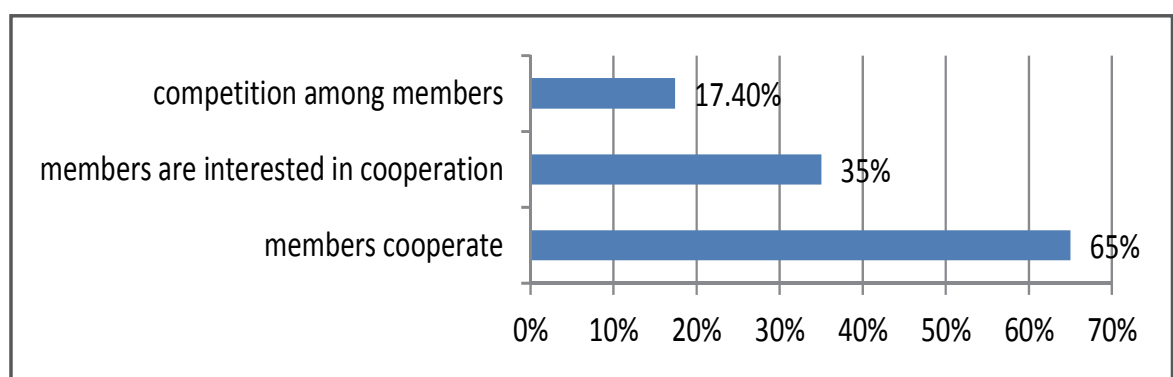

Figure 2 Opinions on relations between LAG members Source: own processing on the basis of questionnaire research, 2014

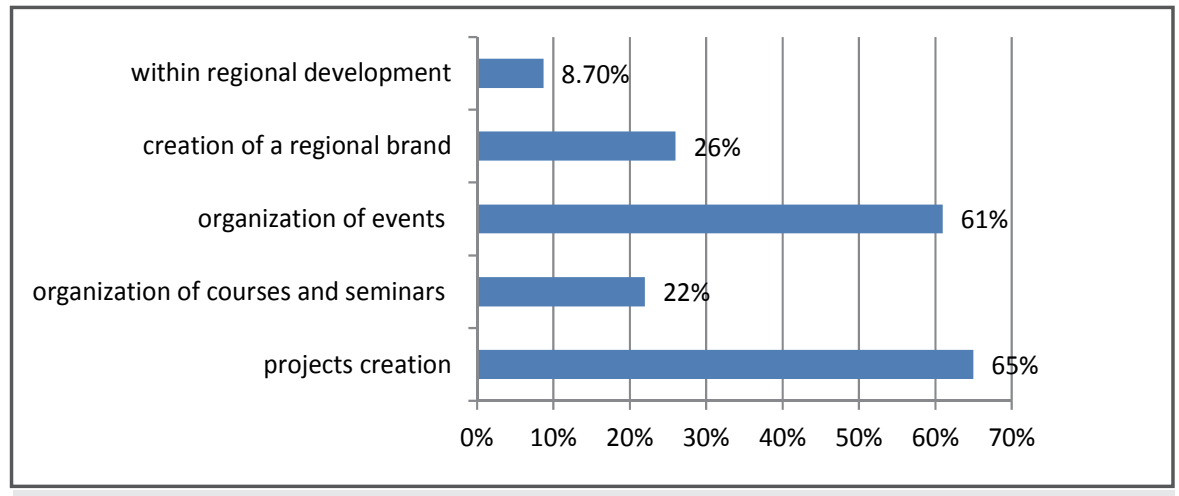

Figure 3 The cooperation area of the LAG members

Source: own processing on the basis of questionnaire research, 2014

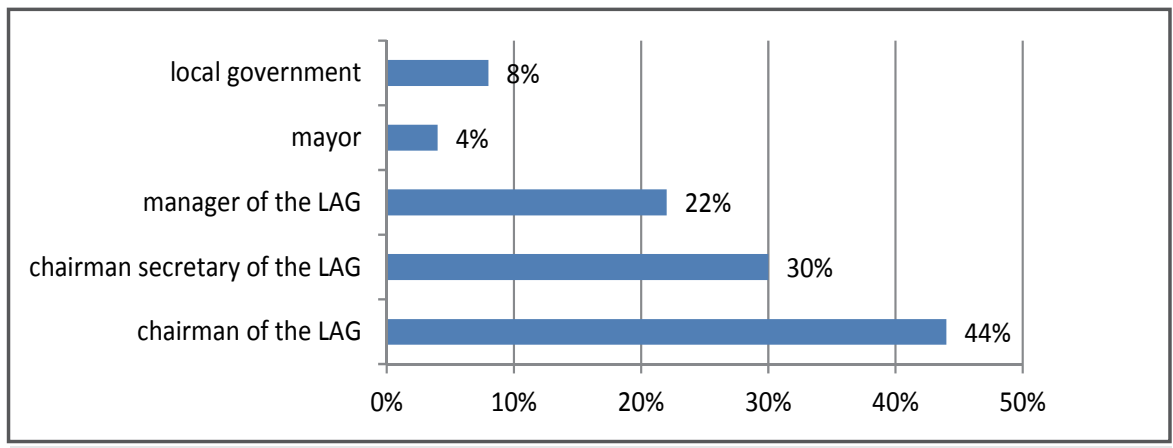

Figure 4 Opinions on the LAG leader

Source: own processing on the basis of questionnaire research, 2014 


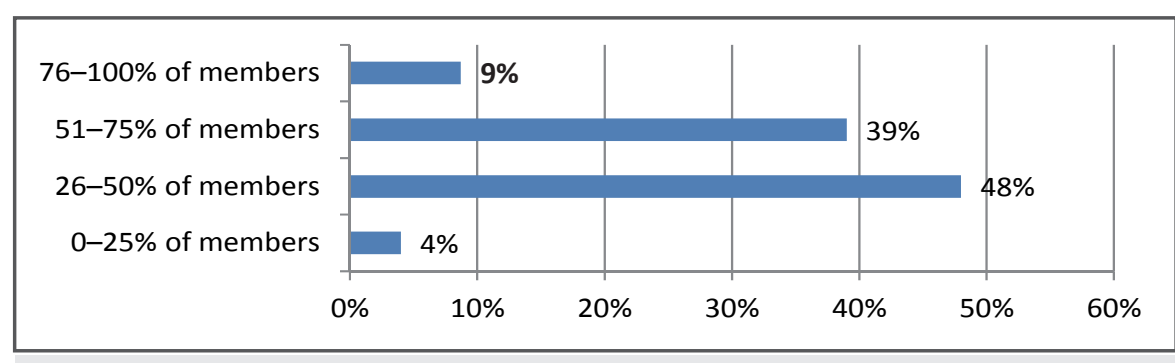

Figure 5 Participate of LAG members in calls Source: own processing on the basis of questionnaire research, 2014

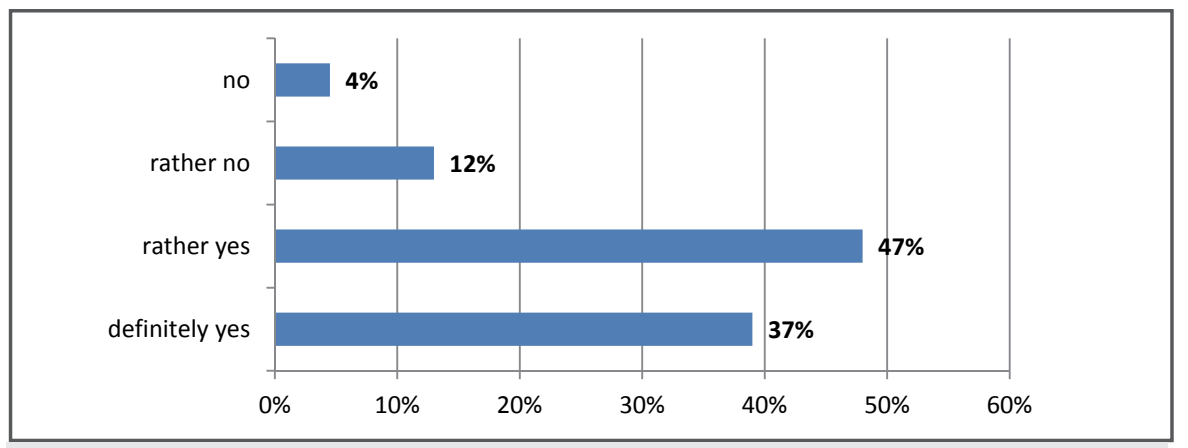

Figure 6 Cooperation of LAG members on project

Source: own processing on the basis of questionnaire research, 2014
$L A G$ 's), in few of $L A G^{\prime}$ 's as the most active appears the civil sector, or both these sectors are equally active. Relations between project managers and members from different sectors are considered as balanced in more than $90 \%$ of LAG's.

More than $80 \%$ of managers think that some members of the LAG are preferred, and as the most common reasons they reported that the direction of axis 4 favors the public sector and are accordingly prefered due to a larger amount of realized projects, easier communication and better cooperation with them. The private sector has considerably fewer options in funding the implementation of the Integrated Local Development Strategy (ILDS), local governments reflect the business requirements within the project proposals and cooperate with them in preparing of projects. There is no preference in terms of decision-making process. chairman of the LAG as the leader of the LAG. Opinions of other respondents shows the Figure 4.

Almost half of managers state that only between quarter and half of LAG members participate in calls for projects. Other manager opinions on participation of LAG members in the calls are presented in Figure 5.

As for the cooperation in project preparation, most of respondents stated that LAG members cooperate during projects preparation. Percentage rate of respondent's answers is shown in Figure 6.
The most of respondents consider the
In more than half of LAG's participates in calls also non-members of the LAG, non-members participate in calls rarely in less than a quarter of $L A G$ 's, and in the remaining $L A G$ do not participate at all. Almost $3 / 4$ of respondents indicated that the implemented projects fulfill adequately the needs of the Local Action Group. The rest of the respondents stated that the LAG's needs are fulfilled by them only partially or not at all.

\section{External relations-Institutional Relations with the Agricultural Paying Agency}

Majority of managers consider communication with the Agricultural Paying Agency (APA) as effective. Signing of Contract with APA is carried out on time, however the controlling process takes too long, in most of cases within one year. The most of respondents agreed that payments are transferred on time, it means it takes from 1 to 3 months. Other answers of respondents are presented in Figure 7.

\section{Relations with the legal environment}

According to the majority of respondents the legislation negatively affects the operation of the $L A G$, makes obstacles to $L A G$, instead of ensuring the progress. Specifically public procurement legislation averts the promotion of the local economy, local producers and service providers. It creates conflict of interest by excluding businesses from competition, causes delays in project management. Additionally it generates bureaucracy for applicants, complicates existence of the local action group, instead of ensuring efficient allocation of resources. It often makes the output procedures more expensive and generates unnecessary bureaucracy, which prevents providing of the needs of the LAG. According to the managers, the Public Procurement Act avoids achieving the principles of the LEADER approach, such as local development by utilising of local resources. It also affects legislation of LAG operation in the area of strategic implementation (for example, changes of the Public Procurement Law, Construction Law). It also has negative affect on yard sale, validity of expenditures for which the rules have changed during the implementation. Managers think that bureaucracy during the approval process increases financial expenditures. Opinions vary, as others think that the setting of the axis 4 causes limitations and complications such as inability to draw from multiple funds (e.g. case of youth work), or small associations compensations excluded NGO from support. Others are adversely assessing the new guidelines of the management authority, while still developing new additions to the strategies and also inexperienced governments.

\section{Relations with local inhabitants}

Participation of the local population in the LAG is limited only to the attendance of

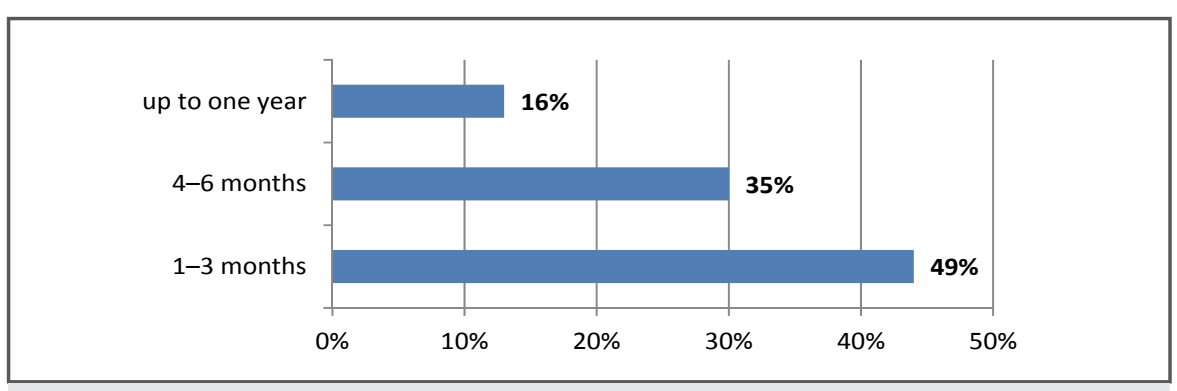

Figure 7 Average time of payment transfer Source: own processing on the basis of questionnaire research, 2014 
activities organized by the Local Action Group. Inhabitants participate in the implementation of projects, decision-making process and emerging of projects ideas in less than $1 / 5$ of $L A G$ 's.

\section{Discussion and conclusion}

The direction of the Axis 4 favors the public sector. The private sector is in the process of implementation of the Integrated Local development strategy significantly limited in possibility of funds spending. It also makes it impossible to spend financial support from multiple funds. The LEADER approach as the only functioning instrument of integrated rural development needs to be supported by the higher financial support from the Rural Development Program (RDP) due to the rural nature of the Slovak Republic area. Support of the Integrated Local Development Strategy should not be limited only to support from the measures of the RDP, since we considered it as insufficient. Also financing from the European Agricultural Fund for Rural Development is insufficient, therefore it should be allowed to receive support from other EU funds, an option may be the financing by the European Regional Development Fund and European Social Fund. Other alternative would be spending of financial resources from other operational programs. It is desirable to increase the participation of the local inhabitants, to enhance their opportunities to participate on controlling process and thus to ensure the transparency and efficiency. The problem is also remaining focus of projects on the calls, so LAG's don't usually have the opportunity to implement projects following their real needs. The amount of financial support for Integrated Local Development Strategy should be dependent on the number of municipalities forming the LAG and the number of people living in the territory of the LAG. It is also necessary to take into account specificities and natural conditions of particular territories in the Slovak Republic.

Municipalities and cities have currently in the LAG more opportunities than entrepreneurs and individuals. There is an obvious effort to increase the interest of LAG's activities and ensure that no members within LAG will be prefered. Municipalities learn how to cooperate with entrepreneurs in particular in the development of rural tourism within the cooperation projects. The private sector is not in the direct focus, the LAG can not adequately support it. In spite of this, based on the principle of solidarity, the private sector supports funding of public sector. Because of this there is dissatisfaction from the side of private and civil sector.

It is also important to make the evaluation process more effective. Control carried out by the APA is excessively time consuming, it takes one year in average. The delay of the evaluation of the calls and the frequently changing rules threaten the successful implementation of the Integrated Local Development Strategy. As for the solution we'd suggest to ensure that the time schedule set in the Grant agreement and Guidelines for the
Administration of Axis 4 LEADER by the APA should be met, regular meetings to develop the guidelines and exchange the experience of the Integrated Local Development Strategy implementation, synchronizing new directives with the Grant agreement.

The performance of the LAG is also negatively affected by the legislation, particularly in public procurement, which does not allow the principles of the LEADER method to be met. By excluding businesses from competition, total subject of procurement is more expensive and not meeting the LAG needs. We believe it is very important to use practical experiences from the LAG's activities by the Managing Authority and the APA, particularly in developing of guidelines for aplicants.

In Slovakia there is currently insufficient use of the area potential and the lack of the financial resources. More effective implementation of the LEADER approach raises the potential to ensure the long term sustainable development of the LAG.

\section{References}

BIDERMAN, A. et al. Kraków 2004. Building Partnerships: A Practical Manual. Polish Environmental Partnership Foundation. ISBN 83-912302-5-2.

COLEMAN, J. S. 1988. Social capital in the creation of human capital. In: Dasgupta, P. Serageldin, I. 2000. eds.: Social Capital. A Multifaceted Perspective, Washington, World Bank.http://wwwwds.worldbank.org/external/default/WDSContentServer/ WDSP/IB/1999/11/19/000094946_9911050536132 4/Rendered/PDF/multi_page. pdf (online 2012-9-10).

FEKETE, É. 2000. A kistérségifejlesztés néhány alapkérdése. Miskolc: Múhelyviták, MTARKK, 2000. ISSN 1585-2554

HUDEC, 0. a i. 2009. Podoby regionálneho a miestneho rozvoja. In: Human and Social capital in regional development, 2009. Košice : Faculty of Economics, 2009. p. 252258. ISBN 978-80-553-0117-4

LIN, N. - ERICKSON, B. H. 2008. Theory, Measurement and the Research Enterprise on Social Capitol. In: Social Capital. An International Research program. Oxford : UP, 2008. ISBN 978-0-19-923438-7.

NIEMI, J. - AHLSTEDT, J. 2007. Finnish Agriculture and Rural Industrie. Helsinki : MTT Economic Research, 2007, 97 p. ISBN 978-951-687-146-5

ONDREJKA, M. 2009. Rural development perspectives 2009. http://www.infovek.sk/ predmety/geografia/prezentacie/Ondrejka_Rozvoj_vidieka.ppt (online 2012-03-03).

PUTNAM, R. 2000. Bowling Alone: the Collapse and Revival of American Community. New York: Simon\&Schuster. ISBN 0-7432-0304-6.

TUBA, L. - SZOMOLAI, V. - KOVÁCS, L. 2006. Building of partnerships, local and regional development. http://www.ngoemanual.org/10_sl.pdf (online 2013-12-09).

\section{Contact adress:}

Ing. Petra Zaujecová, Department of European Policies, Faculty of European Studies and Regional Development, Slovak University of Agriculture in Nitra, e-mail: xzaujecovap@uniag.sk 